\title{
Saharan dust infrared optical depth and altitude retrieved from AIRS: a focus over North Atlantic - comparison to MODIS and CALIPSO
}

\author{
S. Peyridieu ${ }^{1}$, A. Chédin ${ }^{1}$, D. Tanré ${ }^{2}$, V. Capelle ${ }^{1}$, C. Pierangelo ${ }^{3}$, N. Lamquin ${ }^{1}$, and R. Armante ${ }^{1}$ \\ ${ }^{1}$ Laboratoire de Météorologie Dynamique, UMR8539, CNRS/IPSL, Ecole Polytechnique, Palaiseau, France \\ ${ }^{2}$ Laboratoire d'Optique Atmosphérique, Université des Sciences et Technologies de Lille, Villeneuve d'Ascq, France \\ ${ }^{3}$ Centre National d'Etudes Spatiales, Toulouse, France
}

Received: 23 June 2009 - Published in Atmos. Chem. Phys. Discuss.: 8 October 2009

Revised: 10 February 2010 - Accepted: 15 February 2010 - Published: 19 February 2010

\begin{abstract}
Monthly mean infrared $(10 \mu \mathrm{m})$ dust layer aerosol optical depth (AOD) and mean altitude are simultaneously retrieved over the tropics $\left(30^{\circ} \mathrm{S}-30^{\circ} \mathrm{N}\right)$ from almost seven years of Atmospheric Infrared Sounder (AIRS) observations covering the period January 2003 to September 2009. The method developed relies on the construction of look-uptables computed for a large selection of atmospheric situations and follows two main steps: first, determination of the observed atmospheric thermodynamic situation and, second, determination of the dust properties. A very good agreement is found between AIRS-retrieved AODs and visible optical depths from the Moderate resolution Imaging Spectroradiometer (MODIS/Aqua) during the main (summer) dust season, in particular for three regions of the tropical North Atlantic and one region of the north-western Indian Ocean. Outside this season, differences are mostly due to the sensitivity of MODIS to aerosol species other than dust and to the more specific sensitivity of AIRS to the dust coarse mode. AIRS-retrieved dust layer mean altitudes are compared to the Cloud-Aerosol Lidar with Orthogonal Polarization (CALIOP/CALIPSO) aerosol mean layer altitude for the period June 2006 to June 2009. Results for a region of the north tropical Atlantic downwind of the Sahara show a good agreement between the two products $(\sigma \approx 360 \mathrm{~m})$. Differences observed in the peak-to-trough seasonal amplitude, smaller from AIRS, are principally attributed to the large difference in spatial sampling of the two instruments. They also
\end{abstract}

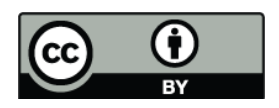

Correspondence to: S. Peyridieu (sophie.peyridieu@1md.polytechnique.fr) come from the intrinsic limit in sensitivity of the passive infrared sounders for low altitudes. These results demonstrate the capability of high resolution infrared sounders to measure not only dust aerosol AOD but also the mean dust layer altitude.

\section{Introduction}

In its fourth report, the Intergovernmental Panel on Climate Change (Forster et al., 2007) notes that, although aerosol forcings are now better understood than at the time of the Third Assessment Report due to improved measurements and more comprehensive modelling, they remain the dominant uncertainty in radiative forcing. Amongst other aerosol species, mineral dust is a major contributor to total aerosol loading and has been the subject of an increasing number of studies. However, most remote sensing studies focus on the solar spectrum, whereas the closure of the terrestrial radiative balance also needs knowledge of the dust effect on terrestrial and atmospheric infrared radiation (Vogelmann et al., 2003). Yet, the dust radiative forcing in the thermal infrared (roughly 3 to $15 \mu \mathrm{m}$ ) cannot be well quantified from measurements in the visible spectrum because refractive index spectra, highly variable, are not reliable enough both in the infrared and in the visible, and because the infrared and visible spectra are not sensitive to the same ranges of particle sizes: the coarse mode (size range $>1 \mu \mathrm{m}$ ) is preferentially observed in the infrared, whereas the accumulation mode $(0.1-1 \mu \mathrm{m})$ is mostly observed in the visible.

Published by Copernicus Publications on behalf of the European Geosciences Union. 

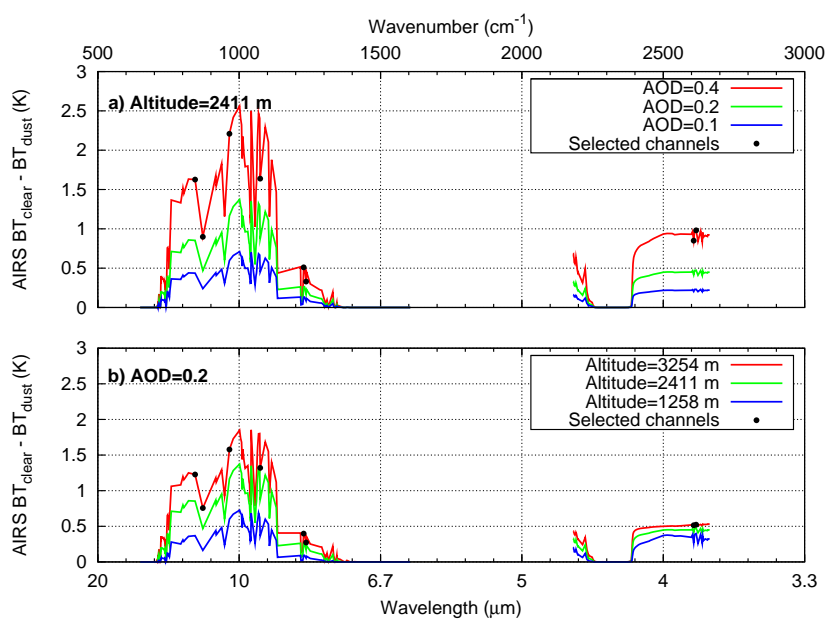

Fig. 1. Effect of mineral dust on AIRS brightness temperatures for 324 AIRS channels: (a) for three values of the $10 \mu \mathrm{m}$ AOD; (b) for three values of the mean layer altitude. "Reference" values: $\mathrm{AOD}=0.2$, altitude $=2411 \mathrm{~m}$.

Remote sensing in the thermal infrared has several other advantages: observations are available both for daytime and nighttime, dust detection is possible over desert (Wald et al., 1998) and, even more important, vertical sounders allow retrieving dust layer mean altitude (Pierangelo et al., 2004, hereafter referred to as Pi2004). Measuring dust altitude may be of great importance for the study of dust transport, dust sources and deposit. Moreover, dust-forced cooling/warming of the atmosphere varies as the dust layer ascends or descends and insufficient knowledge of the three dimensional distribution of dust may cause significant errors in the determination of its effect on climate and in global warming prediction (Claquin et al., 1998; Alpert et al., 2004).

The new generation of high spectral resolution infrared sounders, such as the Atmospheric Infrared Sounder (AIRS) on Aqua, or the Infrared Atmospheric Sounder Interferometer (IASI) on Metop, have already shown promising capabilities to retrieve aerosol properties such as optical depth, altitude, and mean particle size (Pierangelo et al., 2005) from space.

In this paper, following the approach described in Pi2004, infrared optical depth and mean altitude of dust aerosol layer over tropical oceans $\left(30^{\circ} \mathrm{S}-30^{\circ} \mathrm{N}\right)$ are retrieved from AIRS observations covering the seven-year period January 2003 to September 2009. This approach relies on the fact that longwave channels $(8-12 \mu \mathrm{m})$ are sensitive to both the AOD and the altitude of the dust layer whereas shortwave channels (around $4 \mu \mathrm{m}$ ) are essentially sensitive to the dust optical depth (Pi2004). This behaviour, shown on Fig. 1, allows both properties to be retrieved simultaneously. Results are compared to MODIS/Aqua aerosol visible optical depths for the same time period and to Cloud-Aerosol Lidar with Orthogonal Polarization (CALIOP, launched onboard CALIPSO in April 2006 as part of the A-train) aerosol layer altitudes (http://www.icare.univ-lille1.fr/calipso/) for the period June 2006-June 2009. The PARASOL (Polarization and Anisotropy of Reflectances for Atmospheric Sciences coupled with Observations from a Lidar) aerosol products are also used in the comparison. Its main advantage is its capability to discriminate between spherical and non-spherical particles that are in the coarse mode, non-sphericity being an indicator of the presence of dust.

\section{Data and method}

\subsection{Data used for inversion of dust aerosol characteristics: AIRS}

Launched in May 2002 on board the NASA/Aqua platform, AIRS provides high spectral resolution measurements $(\lambda / \Delta \lambda=1200)$ of Earth emitted radiation in the spectral range 3.7 to $15.4 \mu \mathrm{m}$, at a spatial resolution of $13.5 \mathrm{~km}$ (size of the field of view at nadir). A 324 channels subset of AIRS data is currently distributed by NOAA/NESDIS (Goldberg et al., 2003), and archived at Laboratoire de Météorologie Dynamique (LMD) since January 2003. In this study, we use clear-sky, nighttime, AIRS Level-1B brightness temperatures measured over ocean only. Cloud detection follows the method described in Pi2004. The $10 \mu \mathrm{m}$ wavelength, which roughly corresponds to the maximum of the infrared emission from Earth, is chosen therein as the reference wavelength for infrared optical depth.

The method developed follows two main steps. In the first step, the observed atmospheric thermodynamic situation is determined as accurately as possible; in the second step, dust properties are retrieved. Both steps use look-uptables (LUTs) computed for a large selection of atmospheric situations consisting of about two thirds (567) of the 872 tropical situations from the climatological data base "Thermodynamic Initial Guess Retrieval" (TIGR) (Chédin et al., 1985; Chevallier et al., 1998). All radiative transfer simulations are carried out using the fast line-by-line Automatized Atmospheric Absorption Atlas "4A" model (Scott and Chédin, 1981) coupled to the discrete ordinate algorithm (DISORT) (Stamnes et al., 1988) to account for dust particle scattering (see http://ara.lmd.polytechnique.fr/ and http: //www.noveltis.net/4AOP/). The refractive indices of dust are taken from the "mineral transported" (MITR) model of the "Optical Properties of Clouds and Aerosols" (OPAC) data set (Hess et al., 1998, and references therein). The OPAC data set is a revised version of the data published in the book from d'Almeida et al. (1991), and the OPAC mineral transported (MITR) aerosol refractive index mostly comes from the measurements of Volz (1973). 


\subsection{Data used for comparison and validation}

\subsubsection{MODIS}

MODIS has been flying onboard the Aqua platform since May 2002. It is an imager operating in the visible part of the spectrum (36 spectral bands from visible to infrared wavelengths). This instrument is considered as a key sensor for satellite retrieval of aerosol properties. MODIS AOD retrievals have been widely validated with the groundbased sun photometers network AErosol RObotic NETwork (AERONET) data and compared to other satellite retrievals and model simulations (Remer et al., 2002, 2005; Kinne et al., 2003). Like AIRS, MODIS has the advantage of the global scale. Here, we use the $0.55 \mu \mathrm{m}$ MODIS/Aqua AOD product (monthly level-3 data, MYD08_M3.005 products), given on a $1^{\circ} \times 1^{\circ}$ grid, over ocean, for comparison with AIRS from January 2003 to September 2009. MODIS and AIRS flying onboard the same platform Aqua, there are no temporal artefacts on the observed scene. Both products compared here have passed strict cloud filtering tests. Moreover, for the comparison of monthly averages, MODIS $1^{\circ} \times 1^{\circ}$ grid elements corresponding to AIRS cloudy or non-retrieved grid elements have been removed. We thus have the same number of items averaged for both AIRS and MODIS AOD products. Please note that the MODIS aerosol retrieval algorithm over ocean has difficulties for deriving the actual aerosol properties over dusty regions. The nonsphericity of dust introduces artifacts in the retrieved particle size due to the phase function. It results in errors in the spectral dependance of the aerosol optical depth. Levy et al. (2003) evaluated the performance of the MODIS inversion in case of dust particles. The AOD is somewhat underestimated at $0.87 \mu \mathrm{m}$ and overestimated at $0.47 \mu \mathrm{m}$. Nevertheless, the AODs at $0.66 \mu \mathrm{m}$ fall within published estimates (Remer et al., 2002) and MODIS aerosol products provided at $550 \mathrm{~nm}$ are quite accurate enough for our application.

\subsubsection{CALIOP}

CALIOP has been flying onboard the CALIPSO platform since April 2006. CALIOP provides information on the horizontal and vertical distributions of aerosols and clouds, as well as their optical and physical properties over the globe, with high vertical resolution (Winker et al., 2007; Kim et al., 2008).

In order to compare our retrievals from AIRS to the vertical distribution and optical properties of aerosols obtained by CALIOP, we have chosen to use the 5-km (horizontal) Level2 Aerosol Layer Products. At the time of writing, the latest release of this data is version 2.01: this version provides us with the top and base altitude of each detected aerosol layer, the altitude of the centre of the attenuated backscatter coefficient profile ("centroid"), as well as the optical depth (still not considered appropriate for scientific publication, they are not used here) of each layer, at a spatial horizontal resolution of $5 \mathrm{~km}$. These data also include a "feature sub-type classification flag", i.e. information on the aerosol sub-type, and an indication on the amount of horizontal averaging $(5,20$ or $80 \mathrm{~km}$ ) required for an aerosol layer to be detected.

The lidar has a high horizontal resolution of $5 \mathrm{~km}$ for detecting aerosol features. However, CALIOP only makes nadir measurements, and so its global coverage is poorer than a scanning instrument like AIRS due to the distance between two successive orbits (more than $1000 \mathrm{~km}$ ). This is why comparing CALIOP and AIRS products is not straightforward. Comparisons between AIRS and CALIOP have consequently been made on the basis of their respective monthly means. Also, the layer properties algorithm developed for CALIOP can detect up to eight aerosol layers. On the contrary, our dust retrieval algorithm outputs a mean infrared optical depth and a mean altitude of the dust layer, with low sensitivity to a complex layering of the dust due to the limited vertical resolution of the sounder.

With the purpose of a simple and robust evaluation of AIRS retrievals, we have chosen to select cases for which only one aerosol layer is detected and measured by the lidar. This procedure also avoids computing an "average" altitude from various lidar layers with different composition or microphysical properties, which could not be compared with AIRS equivalent altitude, as the infrared effect of these layers might change deeply with composition or properties, especially the median size of particles. The main steps of this selection procedure can be summarized as follows: (1) all CALIOP shots contained in the region of study are selected; (2) selection of the cases with a single aerosol layer; (3) layers flagged as "dust" and "polluted dust" are finally selected, provided this assumption on the aerosol sub-type is "highly confident". The subset of CALIOP data resulting from this selection represents about $64 \%$ of all CALIOP data where aerosol layers are detected.

\subsubsection{PARASOL}

PARASOL was launched in December 2004 and is also part of the A-Train. It carries a POLDER-type instrument (POLarization and Directionality of the Earth Reflectance, see Deschamps et al., 1994) which provides spectral, directional and polarized radiances. The individual foot-print is of $5.0 \times 6.5 \mathrm{~km}^{2}$ and the aerosol product is averaged over a $3 \times 3$ pixel grid, which results in an AOD of $15 \times 19.5 \mathrm{~km}^{2}$ resolution. Over ocean, the inversion algorithm is able to discriminate small spherical particles (accumulation mode) from large spherical or non-spherical particles (coarse mode) (Herman et al., 2005). In the following, the non-spherical component is assumed to be directly related to the presence of dust particles. 

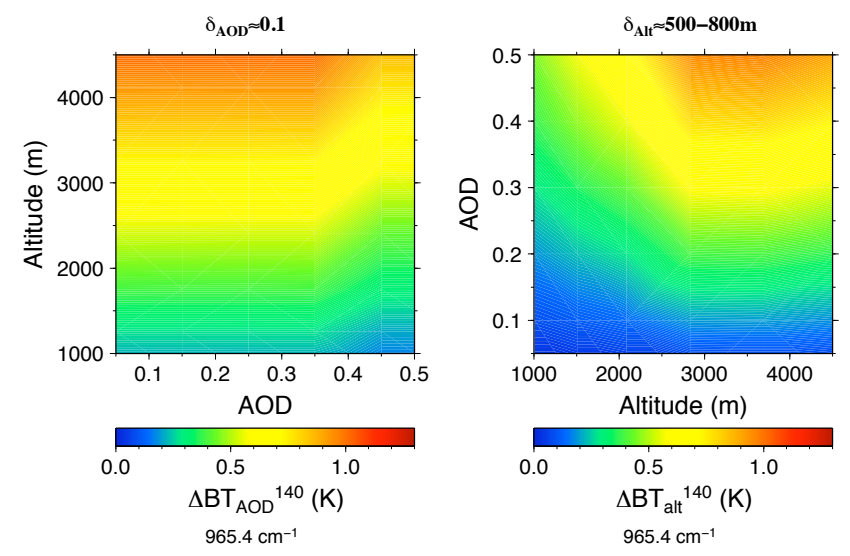

Fig. 2. Sensitivity of channel 140 (at $10.36 \mu \mathrm{m}, 965.4 \mathrm{~cm}^{-1}$ ) to AOD for various mean altitudes of the aerosol layer (left), and to mean layer altitude for various AODs (right). Sensitivity to AOD corresponds to a variation of 0.1 around the AOD value considered; sensitivity to altitude corresponds to a variation of one layer of the $4 \mathrm{~A}$ radiative transfer model layering $(\sim 500 \mathrm{~m}$ below $2400 \mathrm{~m}$ and $\sim 800 \mathrm{~m}$ above) around the altitude value considered. The instrumental noise for this channel is $0.12 \mathrm{~K}$.

\subsection{Method}

\subsubsection{Atmosphere retrieval}

Infrared radiances are primarily sensitive to the atmospheric state (temperature and water vapor profiles). This is why retrieving aerosol properties from infrared observations requires an accurate a priori knowledge of the atmospheric situation observed. For that purpose, 6 channels sensitive to temperature and water vapor and not or almost not sensitive to aerosols have been selected (see Table 1).

For these 6 channels, brightness temperatures (BTs) simulations are then carried out for 7 view angles ( 0 to $30^{\circ}$ by steps of $5^{\circ}$ ), and for 567 atmospheres of the TIGR tropical dataset; results are stored in the atmosphere LUTs. Then, for a given AIRS observation, a distance $d_{0}$ between observed and simulated BTs, taken from the LUT at the closest view angle, is calculated following Eq. (1) where $\mathrm{BT}_{\mathrm{obs}}^{i}$ is the observed brightness temperature and $\mathrm{BT}_{\text {calc }}^{i}$ is the simulated brightness temperature for a given channel $i$.

$d_{0}=\sum_{i=1,7} \frac{\left(\mathrm{BT}_{\mathrm{calc}}^{i}-\mathrm{BT}_{\mathrm{obs}}^{i}\right)^{2}}{\sigma_{i}^{2}}$

The distance is normalized by $\sigma_{i}^{2}$, the variance of channel $i$ over the LUT. Finally, the $N$ best atmospheres, i.e. the $N$ atmospheres with the lowest $d_{0}$, are kept provided they satisfy the criterion $d_{0}<\sim 0.2 d_{\text {lut }}, d_{\text {lut }}$ being the mean distance calculated over the entire atmosphere-LUT, representative of its internal variability. $N$ is up to 10 and situations with $N<5$ are rejected as potentially corresponding to too marginal sit- uations (about 15\% of all cases). This first step, aiming at selecting a reduced set of atmospheric situations corresponding to AIRS observations, is an important improvement added to the method originally published by Pi2004. Incidentally, it also greatly reduces the second step computation time.

\subsubsection{Aerosol monthly mean properties retrieval}

The second step of the algorithm is the retrieval of dust aerosol properties ( $10 \mu \mathrm{m}$ optical depth and mean altitude). First, channels the most appropriate to the retrieval of these two variables are selected as in Pi2004. Selection criteria are: (i) sensitivity to dust, (ii) no sensitivity to ozone, (iii) reduced sensitivity to water vapor. Regarding the sensitivity to dust, a channel is selected either because its sensitivity is high, or because it is well correlated with a far more sensitive channel over a wide range of clear-sky atmospheric situations. This last type of selected channels adds information on other atmospheric variables, such as the temperature profile or water vapor content, thus bringing constraints to the retrieval.

Eight channels have finally been selected (see Table 1 and Fig. 1). As an example, the sensitivity to AOD and altitude of channel 140 at $10.36 \mu \mathrm{m}$ is illustrated on Fig. 2. Sensitivity to AOD (left) is understood as the result of a variation of 0.1 around the value given in abscissa for an altitude given in ordinate. Sensitivity to altitude (right) is understood as the result of a variation of $\sim 500 \mathrm{~m}$ below $2400 \mathrm{~m}$ and $\sim 800 \mathrm{~m}$ above for an AOD given in ordinate (the variable step in altitude is due to the radiative transfer model layering). This figure shows that small AODs still give a significantly larger signal than the noise of the AIRS channel considered (see Table 1) provided the altitude is higher than $\sim 1 \mathrm{~km}$. It also shows that reliable altitude values can hardly be retrieved for small values of the AOD (less than $\sim 0.1$ ).

The aerosol LUTs are built by computing the brightness temperatures for each of the eight channels selected, for the 567 atmospheric situations from the TIGR dataset, 7 viewing angles $\left(0\right.$ to $\left.30^{\circ}\right), 9$ dust AODs ( 0.0 to 0.8 ), and 8 mean altitudes of the layer ( 750 to $\sim 5800 \mathrm{~m}$ ). Table 2 gives all the entries to these LUTs. Data in the LUTs have been either directly computed using the radiative transfer model 4A/DISORT or interpolated (linearly or quadratically) after a proper analysis of the sensitivity of each channel to variations of each of the aerosol properties.

For each AIRS spot (instantaneous field of view, ifov), the aerosol LUT with the view angle the closest $\left( \pm 2.5^{\circ}\right)$ to the real view angle is selected. The set of observed BTs from the eight AIRS channels is compared to calculated sets extracted from this LUT. This comparison is restricted to the $N$ atmospheric situations selected as in Sect. 2.3.1. So, the number of such calculated sets, $P$, is equal to $N$ times the number of AODs and altitudes sampled in the LUT $(\mathrm{N} \times 9 \times 8$; see Table 2). Then, a distance, $D_{\text {spot }}$, is defined between the observed set and each of these $P$ calculated sets: 
Table 1. AIRS selected channels number, wavenumber, wavelength, mean surface transmittance over the tropical situations of the climatological database "Thermodynamic Initial Guess Retrieval" (TIGR) and noise in Kelvin. Upper part of the table: 6 channels selected for atmosphere retrieval. Lower part of the table: 8 channels selected for aerosol retrieval.

\begin{tabular}{ccccc}
\hline $\begin{array}{c}\text { Channel number } \\
1-2378(1-324)\end{array}$ & $\begin{array}{c}\text { Wavenumber } \\
\left(\mathrm{cm}^{-1}\right)\end{array}$ & $\begin{array}{c}\text { Wavelength } \\
(\mu \mathrm{m})\end{array}$ & $\begin{array}{c}\text { Surface } \\
\text { transmittance }\end{array}$ & $\begin{array}{c}\text { Noise }(\mathrm{K}) \\
\text { at 250 K }\end{array}$ \\
\hline $193(87)$ & 704.719 & 14.190 & 0.000 & 0.27 \\
$239(102)$ & 717.994 & 13.928 & 0.002 & 0.24 \\
$1278(176)$ & 1224.623 & 8.166 & 0.074 & 0.13 \\
$1901(251)$ & 2214.572 & 4.516 & 0.068 & 0.10 \\
$2111(285)$ & 2390.110 & 4.184 & 0.054 & 0.14 \\
$2120(294)$ & 2398.949 & 4.168 & 0.421 & 0.15 \\
\hline $587(134)$ & 843.913 & 11.850 & 0.549 & 0.29 \\
$672(135)$ & 871.289 & 11.477 & 0.232 & 0.19 \\
$914(140)$ & 965.431 & 10.358 & 0.675 & 0.12 \\
$1142(166)$ & 1074.478 & 9.307 & 0.330 & 0.13 \\
$1285(177)$ & 1228.225 & 8.142 & 0.568 & 0.08 \\
$1301(179)$ & 1236.539 & 8.087 & 0.246 & 0.08 \\
$2325(313)$ & 2607.887 & 3.835 & 0.606 & 0.35 \\
$2333(315)$ & 2616.383 & 3.822 & 0.974 & 0.31 \\
\hline
\end{tabular}

Table 2. Characteristics of the calculated brightness temperatures look-up-table used for aerosol retrieval. BTs with bold values are calculated directly using the coupled radiative transfer code 4A+DISORT; BTs for other values are interpolated.

\begin{tabular}{|c|c|c|c|}
\hline Parameter & Values & Interpolation mode & Maximum error \\
\hline View angles $\left(^{\circ}\right)$ & $\mathbf{0}, 5,10, \mathbf{1 5}, 20,25, \mathbf{3 0}$ & quadratic & $0.22 \mathrm{~K}$ \\
\hline AOD & $\begin{array}{l}\mathbf{0 . 0}, 0.10,0.20,0.30, \mathbf{0 . 4 0}, 0.50,0.60 \\
0.70, \mathbf{0 . 8 0}\end{array}$ & linear & $0.15 \mathrm{~K}$ \\
\hline Altitude (4A layer) & $\begin{array}{l}\mathbf{7 5 7} \text { m (38), } 1258 \text { m (37), } 1756 \text { m (36), } \\
\mathbf{2 4 1 1} \text { m (35), } 3254 \text { m (34), } 4116 \text { m (33), } \\
4965 \text { m (32), } 5795 \text { m (31) }\end{array}$ & quadratic & $0.20 \mathrm{~K}$ \\
\hline
\end{tabular}

$$
\begin{aligned}
D_{\text {spot }}(\mathrm{AOD}, \text { alt })= & \frac{1}{N} \sum_{a t m=1}^{N}\left(\alpha \sum_{j=1}^{8} \frac{\left(\mathrm{BT}_{\mathrm{calc}}^{j}-\mathrm{BT}_{\mathrm{obs}}^{j}\right)^{2}}{\sigma_{j}^{2}}\right. \\
& \left.+\beta \sum_{k=1}^{5} \frac{\left(\Delta \mathrm{BT}_{\mathrm{calc}}^{k}-\Delta \mathrm{BT}_{\mathrm{obs}}^{k}\right)^{2}}{\sigma_{k}^{2}}\right)
\end{aligned}
$$

where the first term of the sum stands for the normalized distance between the observed and the LUT BTs channel sets. The second term stands for the normalized distance between the observed and the LUT BT differences (gradients) for five couples of channels chosen as 313-177, 177-134, 315-177, 166-135 and 140-134 Pi2004. The coefficients $\alpha$ and $\beta$ ( $\alpha=0.8, \beta=0.2$ ) weight the respective contributions of the individual channels and of the channel differences.

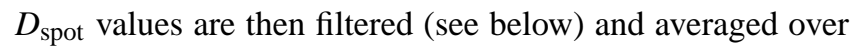
$1^{\circ} \times 1^{\circ}$ grid boxes (pixels):
$D_{\text {pixel }}(\mathrm{AOD}$, alt $)=\frac{1}{N_{\text {spot }}} \sum_{1, N_{\text {spot }}} D_{\text {spot }}(\mathrm{AOD}$, alt $)$

where $N_{\text {spot }}$ stands for the number of AIRS spots kept in the corresponding $1^{\circ} \times 1^{\circ}$ grid box (pixel) after each individual distance $D_{\text {spot }}$ has passed successfully a threshold test based on the internal variability of the LUT.

Figure 3 illustrates, for a $1^{\circ} \times 1^{\circ}$ grid box located near Cape Verde, the values of $D_{\text {pixel }}$ in function of AOD (x-axis) and altitude (y-axis). Finally, AOD and altitude bins with a value of $D_{\text {pixel }}$ verifying $D_{\text {pixel }} \leq \min \left(D_{\text {pixel }}\right) \times 1.1$ are averaged over a month giving the retrieved monthly mean AOD and altitude of the grid box. The standard deviation provides an estimate of the dispersion of the retrieval, keeping in mind that part of this dispersion is due to the natural variability of aerosols. 


$$
\text { Lat }=13.5^{\circ} \mathrm{N} ; \text { Lon }=22.5^{\circ} \mathrm{W}
$$
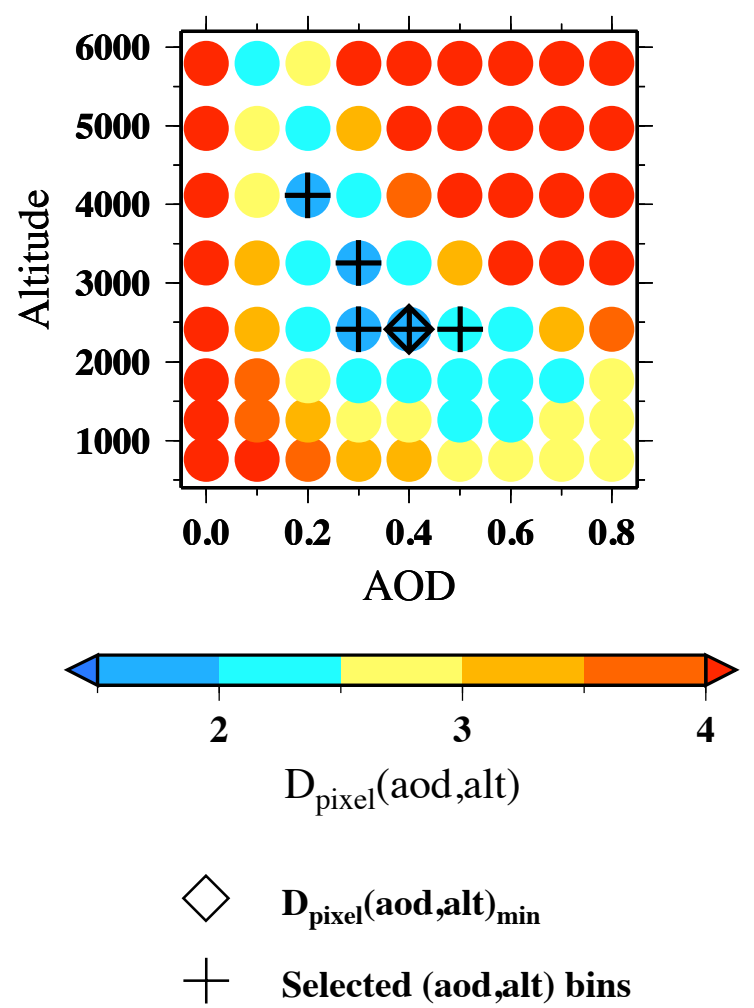

Fig. 3. Representation of the distance calculated for each $\operatorname{AOD}(8$ values on the $\mathrm{x}$-axis)-altitude( 9 values on the y-axis) situation of the aerosol-LUTs. Selected values of $D_{\text {pixel }}$ (AOD,alt) around $D_{\text {pixel }}$ $(\mathrm{AOD}, \text { alt })_{\min }$ (square) are shown with a "+" sign and used for averaging aerosol properties. Here is shown the example of a $1^{\circ} \times 1^{\circ}$ pixel south of Cape Verde Islands in July 2003.

\subsection{Robustness and limits of the algorithm}

Several aspects of the retrieval algorithm: robustness to aerosol model (size distribution, shape, and refractive indices), possible contamination by other aerosol species, radiative transfer model bias removal, or cloud mask including discrimination between clouds and aerosols, etc., were investigated and details may be found in Pi2004. Results show that the effect of a change in the size distribution on the retrieved AOD and altitude is $10 \%$ at the maximum; the impact of asphericity is still smaller than the size impact, below 10\%; the impact of refractive index is trickier since it depends on both the imaginary and real parts of the refractive index at the central wavelengths of the 8 channels.

Pi2004 studied the impact of different refractive indices on the retrieval of aerosol properties. For example, for an input AOD of 0.30 , the errors on the retrieved AOD are of about
$+13 \%$ and $-13 \%$ using MITR or Volz indices, respectively; for an input altitude of $2424 \mathrm{~m}$, the errors on the retrieved altitude are of about $-1 \%$ and $+14 \%$ using MITR or Volz indices, respectively.

Regarding the altitude, observations have shown that dust transport sometimes occurs in two or more distinct layers (Maring et al., 2003a; Mona et al., 2006; Papayannis et al., 2008). Thus, the (unknown) physical thickness of the dust layer and the number of layers are two potential sources of error that were also investigated in Pi2004. Intrinsically, the AIRS-retrieved altitude is an "infrared-equivalent" altitude, i.e. the altitude at which half of the dust optical depth is below and half of the optical depth is above. If the layer is homogeneous, it is the middle of this layer. A sensitivity study has been conducted for a thick single layer case (more than $3 \mathrm{~km}$ thick) and for a 2-layer case (one layer between 2000 and $2800 \mathrm{~m}$ altitude, and a second layer between 3700 and $4600 \mathrm{~m}$ altitude), for about 300 atmospheric situations: in both cases the mean retrieved altitude over the atmospheric TIGR dataset agrees within $200 \mathrm{~m}$ to this definition of the altitude. Furthermore, even if the vertical distribution of dust cannot be retrieved, a homogeneous layer located at the retrieved altitude is, in the infrared, optically equivalent to the real vertical profile. Therefore, it is appropriate for computing dust infrared forcing.

Main limits of the algorithm are: (1) the systematic use of the MITR aerosol model not obviously best adapted to all situations: for example, aerosol layers may have different properties in terms of microphysics over western and eastern Atlantic; (2) the intrinsic difficulty of infrared sounders to measure close to the surface: AODs are reported only for altitudes greater than $1 \mathrm{~km}$; (3) the frequent occurrence of clouds leading to observe a given $1^{\circ} \times 1^{\circ}$ pixel rarely more than 10-12 days per month; (4) the weakness of the aerosol signal for $10 \mu \mathrm{m}$ AODs lower than 0.1. Limits similar to points (3) and (4) also affect visible observations, however to a lesser extent. Point (3) is not without consequences on the retrieved aerosol characteristics if one recalls the high temporal variability of dust events. For example, during the Puerto Rico Dust Experiment (PRIDE) campaign (28 June to 24 July 2000), dust was observed to reside in a deep mixed layer commonly referred to as the Saharan Air Layer (SAL) structure only during the last five days (Reid et al., 2003). During such a short period, the presence of clouds could obscure this event from the satellite view.

\section{A focus on the Saharan air layer over North Atlantic: results and discussion}

Satellite observations show continuous dust transport across the Atlantic ocean from the Saharan sources to the Caribbean and north America in the northern summer and to the Amazon basin during the northern winter (Prospero and Carlson, 1972; Carlson, 1979; Prospero et al., 2002; Koren et al., 
2006). Analysis of satellite data has shown that $\sim 240 \mathrm{Tg}$ of dust are transported annually from Africa to the Atlantic Ocean, $\sim 140 \mathrm{Tg}$ are deposited in the Atlantic Ocean, $\sim 50 \mathrm{Tg}$ fertilize the Amazon Basin, 50 Tg reach the Caribbean, and $20 \mathrm{Tg}$ return to Africa and Europe (Kaufman et al., 2005). Dust export is more abundant in the summer months as a result of large-scale Saharan dust outbreaks (Karyampudi et al., 1999). Summer dust transport to the Atlantic is largely controlled by dust emissions in the north western Sahel (Moulin and Chiapello, 2004). During winter, strong surface winds occur along the southern border of the Sahara, activating sources on the border of the Sahel, notably the Bodélé depression in northern Chad (Koren et al., 2006, and references therein). Dust outbreaks are mostly confined to the SAL, that often extends to 5-6 km in height over west Africa due to intense solar heating in summer months. The airborne dust, which is well mixed within the SAL, is carried westward by the prevailing easterly flow in the latitude belt of $10^{\circ} \mathrm{N}-$ $25^{\circ} \mathrm{N}$ (Karyampudi et al., 1999, and references therein). Approaching the west African coastline, the base of the SAL rises rapidly as it is undercut by the north-easterly trade winds, while the top subsides slowly (Karyampudi et al., 1999). Time variability is also an important characteristic of dust events and, if, as said earlier, dust was observed to reside in the classic SAL layer during the last five days of PRIDE, during the earlier portion of the study dust vertical distributions were considerably more variable, sometimes with the dominant dust load confined to the marine boundary layer (MBL) and sometimes with the dust residing in a uniformly mixed layer extending from near the surface to about $4 \mathrm{~km}$ (Reid et al., 2003). As shown by Chiapello et al. (1995), dust transport occurs at lower altitudes in the trade winds layer during winter months.

Almost seven years (2003 to 2009) of AIRS nighttime observations for the tropical oceans $\left(30^{\circ} \mathrm{S}-30^{\circ} \mathrm{N}\right)$ have been interpreted in terms of dust aerosol monthly mean optical depth and mean layer altitude.

\subsection{Dust optical depth}

\subsubsection{Comparison between $10 \mu \mathrm{m}$ AIRS and $0.55 \mu \mathrm{m}$ MODIS dust AOD: Climatology}

Results are presented for the northern tropics $\left(0^{\circ} \mathrm{N}-30^{\circ} \mathrm{N}\right)$ of the Atlantic Ocean and western Indian Ocean.

Figure 4 compares $10 \mu \mathrm{m}$ AIRS-retrieved (left) and $0.55 \mu \mathrm{m}$ MODIS (right) monthly climatologies $\left(1^{\circ} \times 1^{\circ}\right.$ resolution) of the aerosol mean optical depth for the period 20032008. For significance purposes (see text, Sect. 2.4), AIRS AOD is averaged only for retrievals with layer mean altitude $>1 \mathrm{~km}$. Blank areas correspond to cloudy conditions or no retrievals.

This figure highlights a good general agreement and both products clearly show dust transport from the Saharan sources to the Caribbean and north America in summer and to the Amazon basin in winter. Both products also show a similar decrease of the optical depth from east to west, in coherence with the transport of the dust. The different sensitivity of the two instruments to aerosol particle modes is also to be considered as well as the sensitivity of MODIS to other aerosol types (marine aerosols, for example). Differences seen during winter between $0^{\circ} \mathrm{N}$ and $10^{\circ} \mathrm{N}$ are likely due to the fact that the AIRS product is essentially specific of the dust aerosol coarse mode when the MODIS product mostly integrates the total fine mode aerosol load, including dust, biomass burning (Prospero, 1999; Kaufman et al., 2005), pollution and sea-salt aerosols. Differences observed in the shape of the plume (straight from west to east for MODIS, bending southward for AIRS) could have the same origin. In summer, AIRS AOD remains significant over the Caribbean. This is in agreement with the findings of PRIDE and in particular with the conclusions of Maring et al. (2003a,b) who note that the normalized mineral dust size distributions of particles smaller than $7.3 \mu \mathrm{m}$ (coarse mode) over the Canary Islands and Puerto Rico were indistinguishable, indicating that coarse mode particles were not preferentially removed during atmospheric transport. During the same campaign, Reid et al. (2003) report that, in most circumstances, gravitational settling does not appear to be an important factor in dictating dust vertical distribution.

Over the Indian Ocean, the dust season as seen by AIRS starts earlier, by about two months, than seen by MODIS. This is discussed in Section 3.1.2.

\subsubsection{Comparison between $10 \mu \mathrm{m}$ AIRS and $0.55 \mu \mathrm{m}$ MODIS monthly mean AOD time series}

This good overall agreement is confirmed by Fig. 6 which shows time series (2003-2009) of the $10 \mu \mathrm{m}$ AIRS AOD and of the $0.55 \mu \mathrm{m}$ MODIS AOD averaged over three regions of the northern tropical Atlantic downwind of the Sahara, and one region south of the Arabian peninsula. The boundaries of these regions are shown in Fig. 5.

Near the African continent Fig. 6a, the agreement between the two AOD time series appears quite good particularly during the dust season, from April to October. Both products show similar interannual variability with, for example, slightly weaker signatures for the years 2004 and 2008 in region (a). Outside the dust season, differences are probably explained by the sensitivity of MODIS to aerosols other than dust and to the accumulation mode (indeed MODIS inversion includes various accumulation and coarse mode combinations) instead of the coarse mode. As explained by Kaufman et al. (2005), the secondary MODIS winter peaks are most probably due to biomass burning smoke from savanna fires in the Sahel, eventually embedded in dust. For the southern tropics (not shown), a strong signature is present on the MODIS time series from May/June to September/October, in phase with the southern hemisphere fire season (Giglio et al., 2006). This signature is not seen in the AIRS AOD, as 

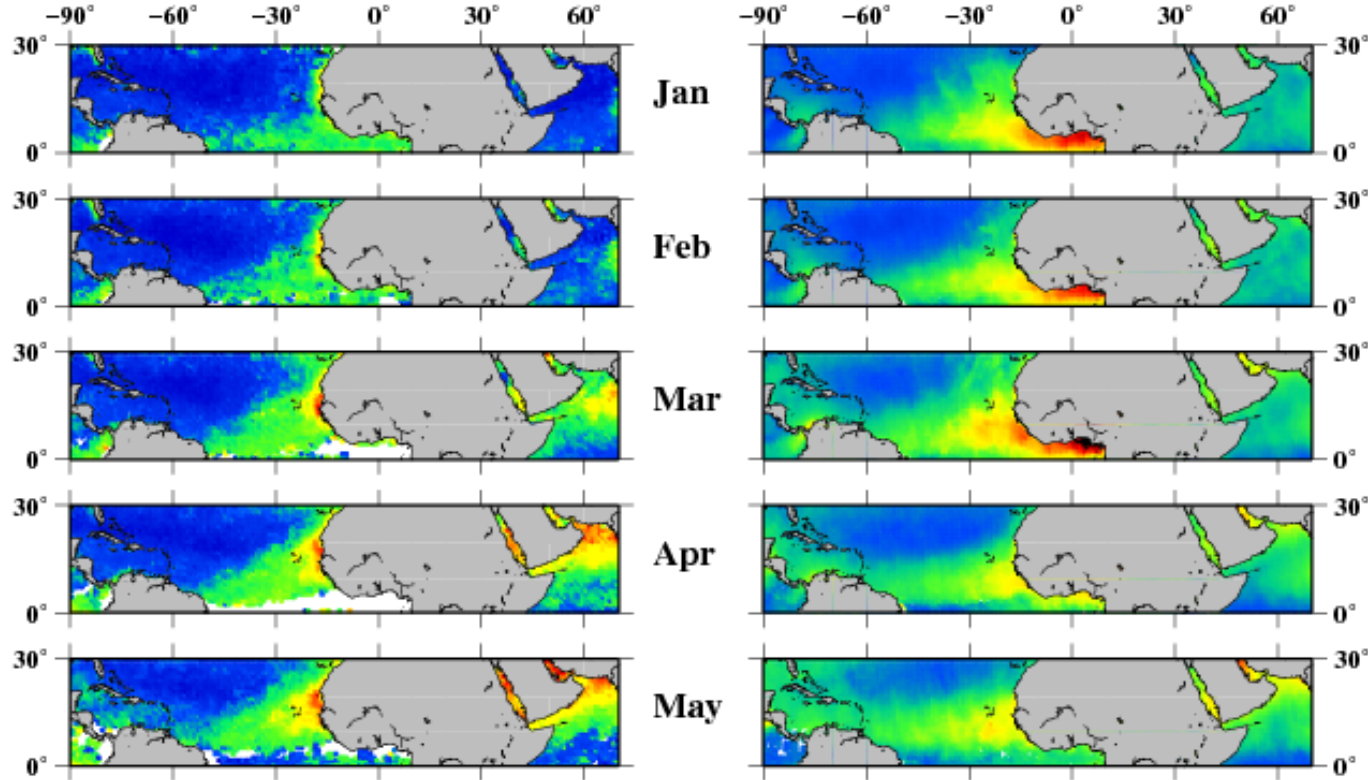

May
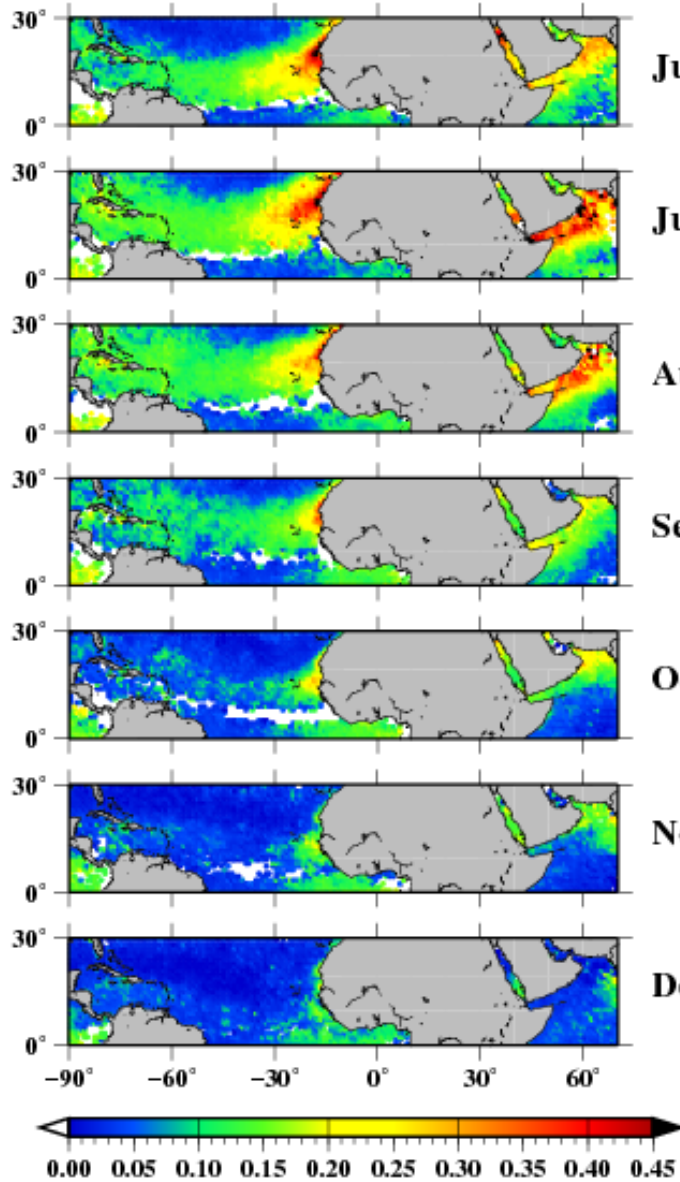

AIRS AOD $(10 \mu \mathrm{m})$
Mar

Apr

Jun

Jul

Aug

Sep
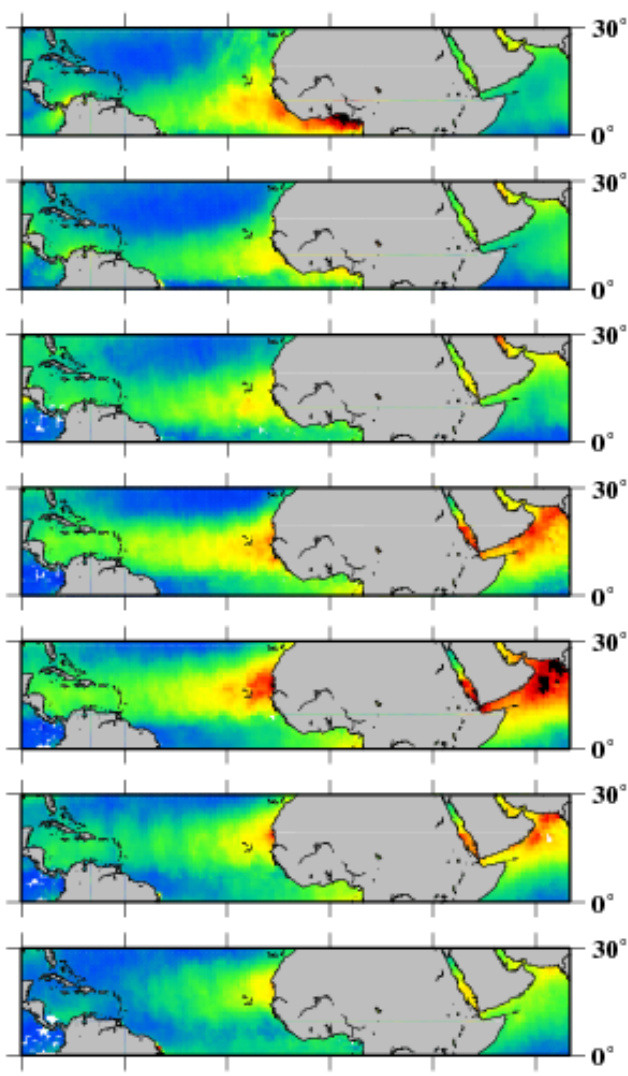

Oct

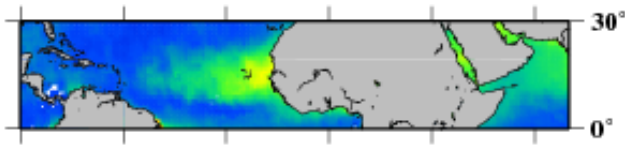

Nov

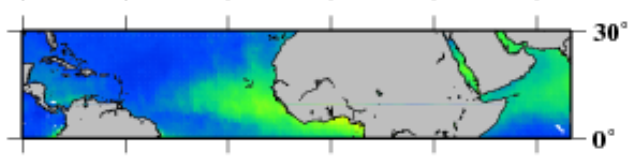

Dec

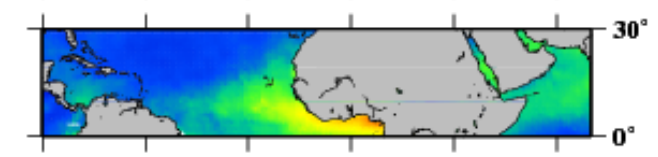

$-90$

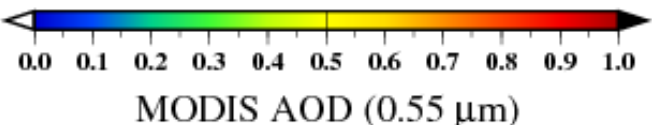

Fig. 4. Monthly climatology $\left(1^{\circ} \times 1^{\circ}\right.$ resolution) of the aerosol layer mean optical depth seen by AIRS and MODIS over the period 20032008. Left: $10 \mu \mathrm{m}$ AIRS-retrieved AODs; right: $0.55 \mu \mathrm{m}$ MODIS-retrieved AODs. January: top; December: bottom. 


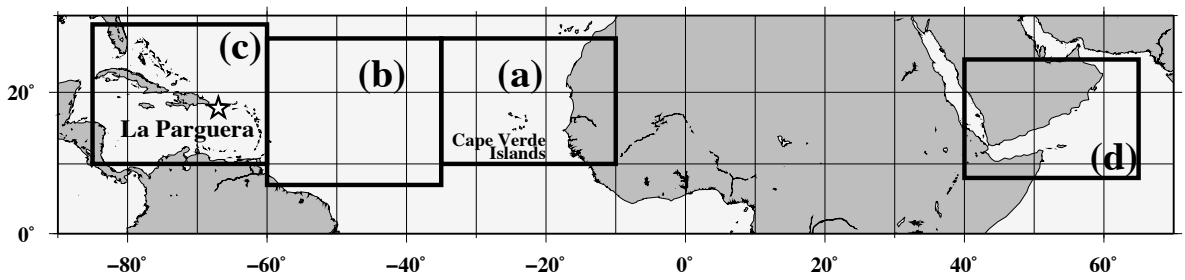

Fig. 5. Regions of study and location of the La Parguera AERONET station $\left(18^{\circ} \mathrm{N}, 67^{\circ} \mathrm{W}\right)$.
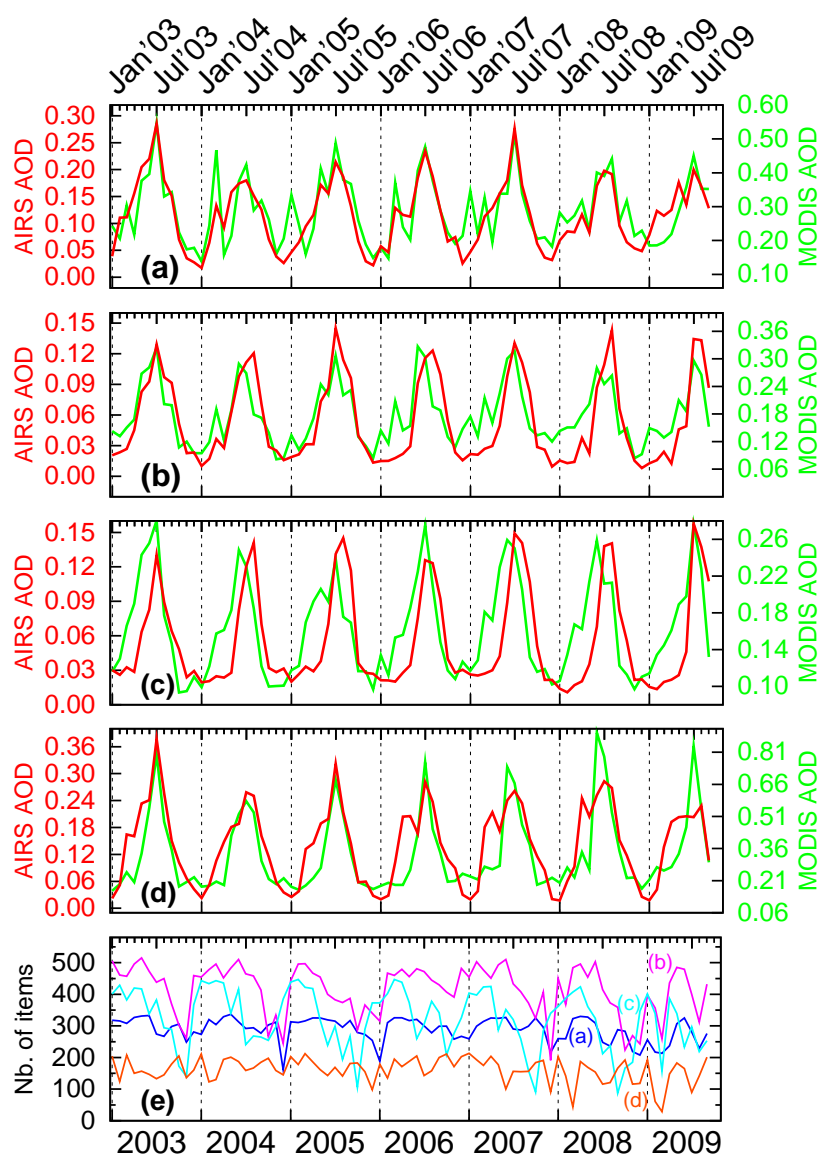

Fig. 6. (a) to (d) Time series of $10 \mu \mathrm{m}$ AIRS (red line, left ordinate) and $0.55 \mu \mathrm{m}$ MODIS (green line, right ordinate) optical depths for the regions of Table 3: (a) east Atlantic, (b) middle Atlantic, (c) west Atlantic, and (d) south of the Arabian peninsula. (e) Time series of the number of items found in the corresponding regions.

expected from the method. For the other months, the agreement is satisfactory. Similar conclusions are obtained for region (b) (Fig. 6b) with, however, less prominent winter secondary peaks.

Region (c) (Fig. 6c) shows an AIRS AOD season lagging behind the MODIS AOD season. We see two tentative explanations to this phenomenon: (1) a start of the dust sea- son very far from the sources dominated by the fine mode not seen by AIRS; (2) the use of the MITR aerosol model not obviously adapted to this situation (McConnell et al., 2008). The optical depth of the non-spherical coarse mode derived from PARASOL is reported in Fig. 7 for May, June and July 2007: region (c) is obviously on the edge of the dust plume in May/June, when dust is covering the area in July. AERONET measurements made at La Parguera $\left(18^{\circ} \mathrm{N}\right.$, $\left.67^{\circ} \mathrm{W}\right)$ station, which is close to the center of the box, show the same tendency (Fig. 8) as PARASOL ; In May, values of the visible optical depth at $550 \mathrm{~nm}$ and Angström exponent from AERONET measurements are 0.19 and 0.69, respectively. This is in agreement with MODIS mean optical depth, which ranges from 0.18 to 0.24 throughout the years 2003 to 2009. These values show that although the visible optical depth is already high in May, it is only due to small particles. On the contrary in June and July, AERONET 0.55 $\mu \mathrm{m}$ AOD series is highest when the corresponding Angström exponent is lower than 0.40 , indicating the presence of coarse mode particles. This peak of the visible optical depth corresponds to the peak of our AIRS-retrieved infrared optical depth. The transition between two aerosol modes in May/June may explain the time lag seen between MODIS and AIRS observations. It is however worth pointing out that, for this region, both AOD and altitude approach the level of significance (see next section) and AIRS results are probably less reliable than for the previous two regions. A deeper analysis of this problem is needed before concluding.

Region (d) (Fig. 6d), south of the Arabian peninsula, shows peaks in rather good agreement with MODIS and confirms the early start of the AIRS seasonal signal seen in Figure 4. As for region (a), MODIS baseline AOD remains relatively high $(\sim 0.20)$ and starts increasing later, by about two months, than does AIRS AOD. For the four last years (20062009), AIRS shows two peaks, the main one in July and the secondary one in April/May. This is compatible with Léon and Legrand (2003) results who report observed maxima of activity in dust sources during pre-monsoonal (spring) and monsoonal (summer) periods, with active areas during spring time between $17^{\circ} \mathrm{N}-22^{\circ} \mathrm{N}$ and $42^{\circ} \mathrm{E}-58^{\circ} \mathrm{E}$. Also, Li and Ramanathan (2002) show monthly variation of the AVHRRretrieved AOD averaged over the 5 years from 1996 to 2000 for the Arabian Sea with an early start of the season in April 


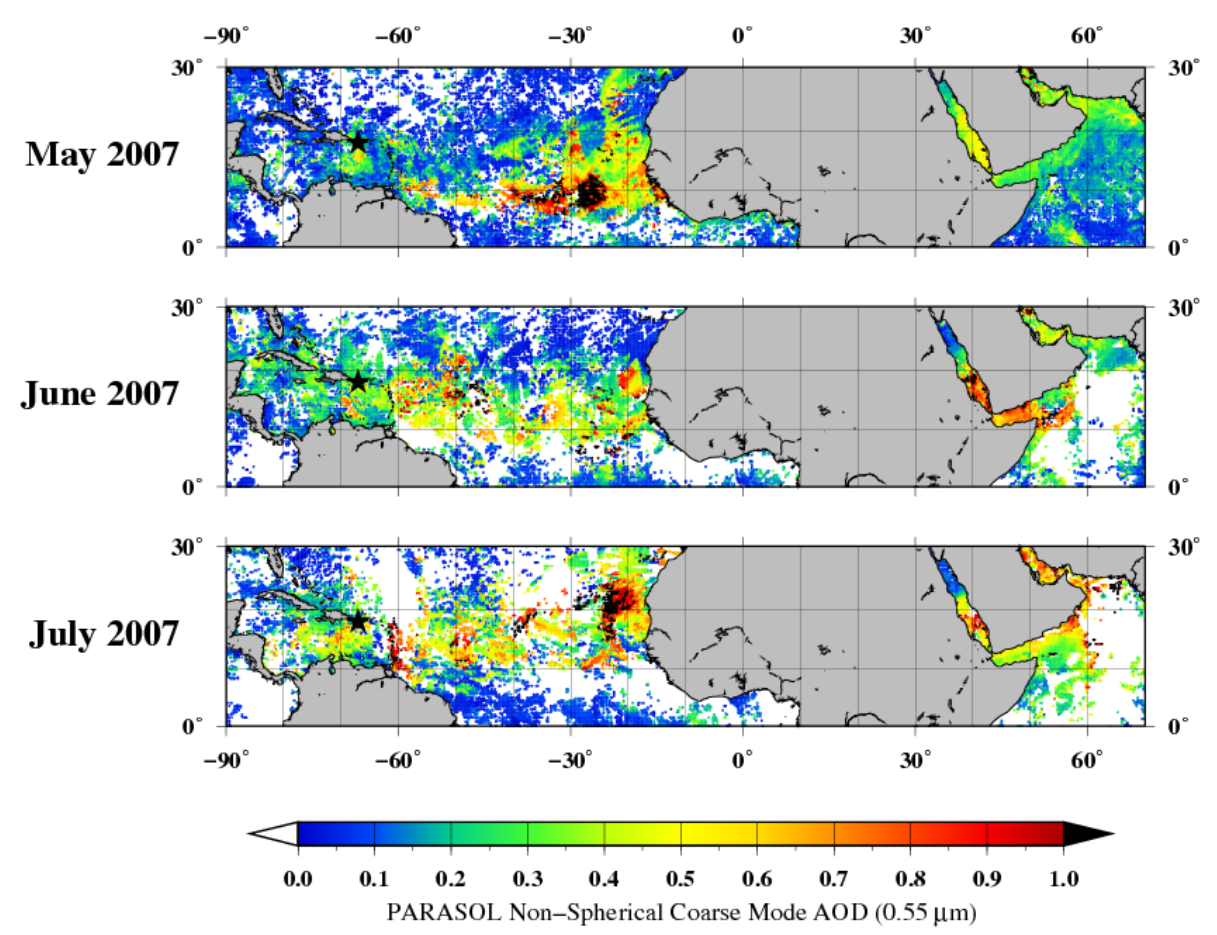

Fig. 7. Aerosol optical depth of the non-spherical coarse mode at $0.55 \mu \mathrm{m}$ observed by PARASOL in May (top), June (center) and July (bottom) 2007.

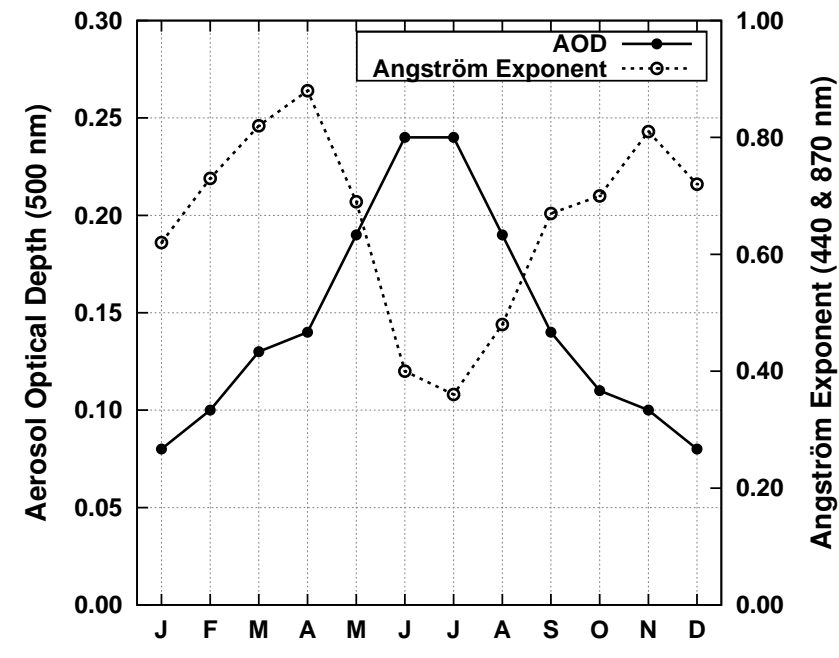

Fig. 8. Aerosol optical thickness (y-left axis) and Angström Exponent (y-right axis) as a function of the month (x-axis). The data are averaged over 8 years of measurements, from 2000 to 2008 (2003 is missing). (see their Fig. 7). However, the AIRS AOD results should be taken with care because of the simultaneously retrieved aerosol layer mean altitude approaching the limit of reliability of $1 \mathrm{~km}$ (see Sect. 2.4).

Altogether, during the dust season, a good correlation is observed between the two products: $R^{2}=0.65$ for both regions (a) and (b), $R^{2}=0.52$ for region (d); for region (c), as expected from the difference in the phase of the two products, the correlation is substantially lower: $R^{2}=0.31$. Using the AERONET retrievals over Cape Verde (effective radius and width of coarse and accumulation modes from Dubovik and King, 2000), the refractive indices at $0.55 \mu \mathrm{m}$ used by MODIS retrieval, and the refractive indices at $10 \mu \mathrm{m}$ from the MITR model, Pi2004 computed with a Mie radiative transfer code the infrared to visible extinction ratio. The calculated ratio of 0.40 to 0.55 depending on the month compares well with the AIRS to MODIS AOD ratio of 0.40 to 0.52 for a small area over Cape Verde (JJA). However, it must be underlined that AERONET size distribution retrievals are available only 2 to 5 days each month, whereas the AIRS to MODIS ratio is a season average. We also find a slight decrease of this ratio when the distance to the sources increases: 0.50 for region (b), which may reveal a small loss in coarse size particles due to gravitational settling. This ratio then increases to 0.64 for region (c) manifesting again the difference in phase between the fine and the coarse modes during this season (later arrival of the coarse mode). These numbers also 


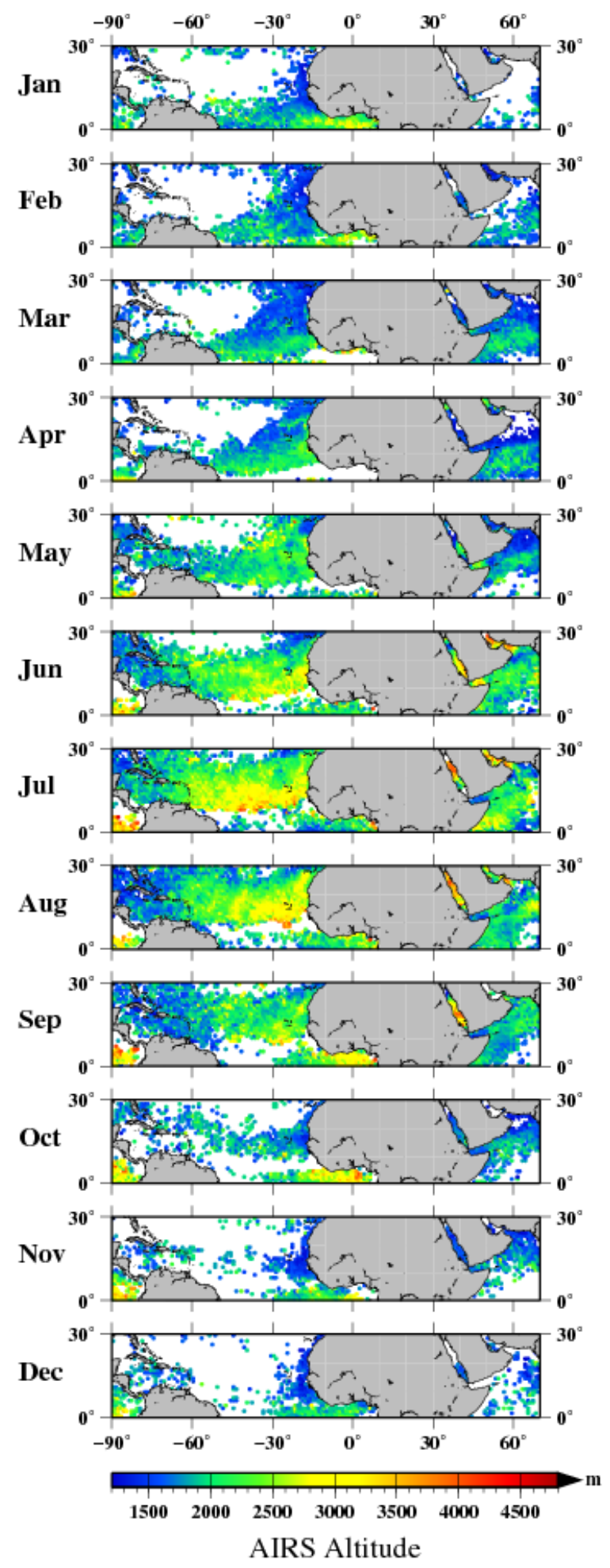

Fig. 9. Monthly climatology $\left(1^{\circ} \times 1^{\circ}\right.$ resolution $)$ of the aerosol layer mean altitude retrieved by AIRS over the period 2003-2008. For significance purposes (see text, Sect. 2.4), altitude is shown only for pixels with $10 \mu \mathrm{m} A O D \geq 0.10$.

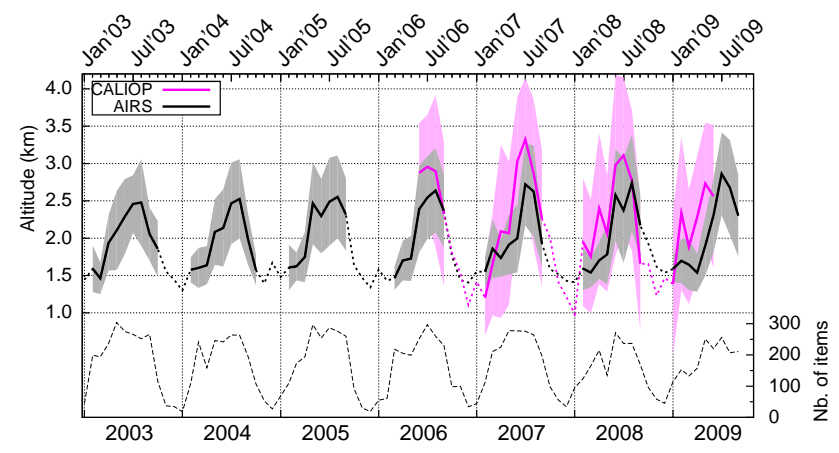

Fig. 10. Time series of AIRS-retrieved monthly mean aerosol layer altitude (thick black line, solid if the number of items is statistically representative, dotted otherwise) over Atlantic region (a) of Table 3. The thin dashed line shows on the right ordinate the corresponding number of items in the region. The $1-\sigma$ envelope of the AIRS retrieval over the region is shown in grey. CALIOP mean (centroid) altitudes are shown in magenta for the period June 2006-June 2009, with associated $1-\sigma$ envelope.

compare well with the results of Highwood et al. (2003). Figure $6 \mathrm{e}$ also shows the number of items found in each region and considered for averaging optical depth monthly mean products. It depends on the size of each region as well as on the number of AIRS retrievals (generally smaller outside the dust season, as seen in particular for regions (b) and (c)).

\subsection{Dust altitude}

\subsubsection{AIRS mean layer altitude climatology}

Altitude results are first presented spatially, from the northern tropical Atlantic to the western Indian Ocean.

Figure 9 shows AIRS-retrieved monthly climatology $\left(1^{\circ} \times 1^{\circ}\right.$ resolution $)$ of the aerosol layer mean altitude for the period 2003-2008. For significance purposes (see text, Sect. 2.4), altitude is shown only for pixels with $10 \mu \mathrm{m}$ $A O D \geq 0.10$. Locally, altitude reaches $\sim 3500 \mathrm{~m}$ in July and August (mean over 6 years) and it is worth recalling that it represents the mean altitude of the dust coarse mode layer, with about half the AOD above and half below.

Results of Fig. 9 show: (1) a slow regular decrease of the altitude from east to west reported in several studies (see, for example Colarco et al., 2003a,b, and references therein), and (2) during the peak of the dust season, a positive northsouth gradient. The north-south gradient observed here was already noticed in Pi2004 and is confirmed by this 6-year climatology. It could be explained by uplifting at the Intertropical Convergence Zone (ITCZ), located near $10^{\circ} \mathrm{N}$ in July. This hypothesis is in agreement with Colarco et al. (2003b), whose model simulations show a positive vertical mass flux around the ITCZ. Similarly, Karyampudi et al. (1999) tentatively explain the particular behaviour of the southern edge of 
the SAL by vertical mixing induced by strong vertical wind shears associated with the middle-level jet as well as by penetrating cumulous clouds. On the AOD and altitude maps of Figs. 4 and 9, the blank areas south of the SAL are mostly due to persistent cloudiness and precisely correspond to the location of the ITCZ.

\subsubsection{AIRS dust layer monthly mean altitude time series and comparison to CALIOP-altitude product}

Figure 10 shows AIRS-retrieved dust layer monthly mean altitude time series (from January 2003 to September 2009) averaged over region (a) of Fig. 5. A clear seasonal cycle is seen, with the monthly mean altitude (thick solid line) being higher during summer (June-September) than during winter (November-January). This transport pattern is consistent with conclusions from other studies (see, for example, Prospero et al., 1981, Chiapello et al., 1995), the latter reporting higher altitudes in summer, with transport within the Saharan Air Layer (SAL), than in winter, with transport within the shallower easterly wind layer. Figure 10 also displays the standard deviation associated with AIRS monthly mean altitude ( $\pm 1 \sigma$, shaded) calculated from all items found in the region and for each month. Over the period processed and for the dust season, the mean standard deviation comes to about $360 \mathrm{~m}$. The bottom dashed line shows the number of AIRS items (right ordinate) available for the statistics and indicates that less confidence must be given to winter months. For the period June 2006-June 2009, CALIOP-retrieved mean aerosol layer altitude product (centroid) is shown by the magenta solid line (see Sect. 2.2.2 describing how CALIOP Level-2 data are selected).

The agreement between AIRS and CALIOP mean altitude is satisfactory keeping in mind: (1) the extreme difference between the spatial sampling of the two instruments, and (2) the large standard deviation associated with CALIOP altitudes (vertical magenta thin lines). The difference seen between the peak-to-trough amplitudes of the two products (smaller for AIRS) likely results from the large difference between their spatial resolutions. The spatial averaging of AIRS is indeed expected to smooth local extreme values measured by CALIOP. During the main dust season (JuneSeptember), AIRS altitudes are lower than CALIOP altitudes by about $300 \mathrm{~m}$; better agreement is found outside of the main dust season. This low bias likely results from the difference in the definition of the "mean aerosol layer altitude" used by CALIOP (the so-called "centroid" that we verified being very close to the mean of the top and base altitudes, at least for the single-layer cases processed here) and AIRS. For the latter, the altitude retrieved is an "infrared-equivalent" altitude, i.e. the altitude at which half of the dust optical depth is below and half of the optical depth is above (see Sect. 2.4). If the layer is homogeneous, it is the middle of this layer, as for CALIOP. It may however be expected that such layers are not homogeneous and that half of the AOD is concen- trated in a layer geometrically thinner below the "infraredequivalent altitude" and thicker above. Moreover, it must be kept in mind that CALIOP is also sensitive to high level fine mode dust particles. This comparison illustrates the ability of infrared sounders to retrieve dust aerosols altitude quite accurately.

\section{Conclusions}

Infrared $(10 \mu \mathrm{m})$ dust aerosol AOD and mean altitude have been retrieved over the tropics $\left(30^{\circ} \mathrm{N}-30^{\circ} \mathrm{S}\right)$ from AIRS observations, covering the period January 2003-September 2009. AIRS AODs compare well with MODIS $0.55 \mu \mathrm{m}$ AOD for three regions positioned over northern tropical Atlantic, from west to east downwind of the Sahara and one region of the Indian Ocean, south of the Arabian peninsula. This agreement is particularly good both during and outside the main (summer) dust seasons and differences between the two products mostly highlight the sensitivity of MODIS to biomass burning (not to speak of pollution or seasalt aerosols) outside these seasons. For the region of the Atlantic Ocean the farthest from the sources, the AIRS AOD season lags behind the MODIS AOD season. We proposed two tentative explanations to this phenomenon: (1) a start of the dust season very far from the sources dominated by the fine mode not seen by AIRS, seemingly confirmed by PARASOL-retrieved aerosol optical thickness of the nonspherical mode at $0.55 \mu \mathrm{m}$; (2) the use of the MITR aerosol model not ideally suited to this situation. The ratio $10 \mu \mathrm{m}$ AOD to $0.55 \mu \mathrm{m}$ AOD does not show an important interannual variability.

AIRS-retrieved dust mean layer altitude shows a slow regular decrease from east to west Atlantic already reported in several studies as well as a clear seasonal cycle, with summer transport occurring at higher altitudes than spring transport, in agreement with former studies (Prospero et al., 1981; Chiapello et al., 1995). A north-south positive gradient observed (Pi2004) is confirmed here during the peak of the dust season and could be explained by uplifting at the Intertropical Convergence Zone, located near $10^{\circ} \mathrm{N}$ in July (Colarco et al., 2003b; Karyampudi et al., 1999). For the period June 2006June 2009, the comparison with CALIOP/CALIPSO mean altitude (centroid) of the dust layer shows a good agreement with the AIRS mean altitude. This comparison was limited to cases where the lidar detect only one aerosol layer (about $64 \%$ of the cases). The difference seen between the peakto-peak amplitudes of the two products (smaller for AIRS) is thought to come mainly from the large difference between the spatial resolutions of the two instruments.

These results illustrate the ability of infrared sounders to retrieve dust layer $10 \mu \mathrm{m}$ AOD as well as mean dust layer altitude quite accurately. Limits of this approach are mostly due to the intrinsic limit of infrared sounders to sound close to the surface. As a consequence, retrieved altitudes lower than 
$1 \mathrm{~km}$ (less than $5 \%$ of all cases in dusty regions) have been discarded. The still too limited number of accurate refractive index measurements for various dust species in the infrared must also be underlined. We hope that additional measurements (see for example, McConnell et al., 2008) will be conducted, allowing deeper study of the impact of dust composition and opening the way to promising dust mineralogical characterizations from high spectral resolution satellite observations. The next step is to extend the retrieval to daytime observations and over land, which requires consideration of the infrared surface emissivity at high spectral resolution now available at LMD (Péquignot et al., 2008). These new developments are presently underway at LMD on the basis of observations made by the new very high resolution Infrared Atmospheric Sounder Interferometer (IASI), offering more and still cleaner channels. This will provide a unique global monitoring of dust sources over desert.

Finally, a satisfactory agreement has been found comparing the different retrievals from AIRS, MODIS and CALIOP. As reported by Liu and Mishchenko (2008), comparison of aerosol datasets from different satellite-based instruments is challenging. Each retrieval has its own limitations and shortcomings so large differences may occur. The present algorithm is no exception and users should be aware of the conditions of use and of the quality statements of the product.

Acknowledgements. We thank N. A. Scott, C. Crevoisier, and $\mathrm{X}$. Briottet for their help and fruitful discussions. MODIS data were obtained through NASAs Giovanni, an online visualization and analysis tool maintained by the Goddard Earth Sciences (GES) Data and Information Services Center (DISC). We are also happy to thank the ICARE Thematic Center for providing us with CALIPSO/CALIOP and PARASOL data (http://www.icare.univ-lille1.fr/). We thank S. Marchand for technical support with CALIPSO code and F. Ducos for handling PARASOL data. Finally, we thank AERONET and B. N. Holben for operating the La Parguera site.

Edited by: P. Jöckel

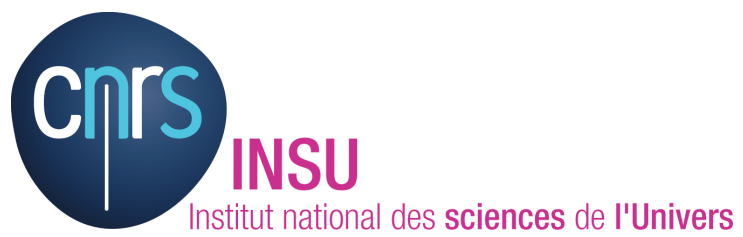

The publication of this article is financed by CNRS-INSU.

\section{References}

Alpert, P., Kishcha, P., Shtivelman, A., Krichak, S., and Joseph, J.: Vertical distribution of Saharan dust based on 2.5-year model predictions, Atmos. Res., 70, 109-130, doi:10.1016/j.atmosres.2003.11.001, 2004.
Carlson, T.: Atmospheric turbidity in Saharan dust outbreaks as determined by analyses of satellite brightness data, Mon. Weather Rev., 107, 322-335, 1979.

Chédin, A., Scott, N. A., Wahiche, C., and Moulinier, P.: The Improved Initialization Inversion Method: A high resolution physical method for temperature retrievals from satellites of the TIROS-N series, J. Clim. Appl. Meteorol., 24, 128-143, 1985.

Chevallier, F., Cheruy, F., Scott, N. A., and Chédin, A.: A neural network approach for a fast and accurate computation of a longwave radiative budget, J. Appl. Meteorol., 37, 1385-1397, 1998.

Chiapello, I., Bergametti, G., Gomes, L., Chatenet, B., Dulac, F., Pimenta, J., and Santos Soares, E.: An additional low layer transport of Sahelian and Saharan dust over the North-Eastern Tropical Atlantic, Geophys. Res. Lett., 22, 3191-3194, doi:00948534/95/95GL-0.3313, 1995.

Claquin, T., Schulz, M., Balkanski, Y., and Boucher, O.: Uncertainties in assessing radiative forcing by mineral dust, Tellus, 50B, 491-505, 1998.

Colarco, P., Toon, O., and Holben, B.: Saharan dust transport to the Caribbean during PRIDE: 1. Influence of dust sources and removal mechanisms on the timing and magnitude of downwind aerosol optical depth events from simulations of in situ and remote sensing observations, J. Geophys. Res., 108, 8589, doi:10.1029/2002JD002658, 2003a.

Colarco, P., Toon, O., Reid, J., Livingston, J., Russel, P., Redemann, J., Schmid, B., Maring, H., Savoie, D., Welton, E., Campbell, J., Holben, B., and Levy, R.: Saharan dust transport to the Caribbean during PRIDE: 2. Transport, vertical profiles, and deposition in simulations of in situ and remote sensing observations, J. Geophys. Res., 108, 8590, doi:10.1029/2002JD002659, 2003b.

d'Almeida, G., Koepke, P., and Shettle, E.: Atmospheric Aerosols: Global Climatology and Radiative Characteristics, A. Deepak Publishing, Hampton, Virginia 23666-1340, USA, 1991.

Deschamps, P.-Y., Breon, F.-M., Leroy, M., Podaire, A., Bricaud, A., Buriez, J.-C., and Sèze, G.: The POLDER mission: Instrument characteristics and scientific objectives, IEEE T. Geosci. Remote, 32, 598-615, 1994.

Dubovik, O. and King, M. D.: A flexible inversion algorithm for retrieval of aerosol optical properties from sun and sky radiance measurements., J. Geophys. Res., 105, 20673-20696, doi:10.1029/2000JD900282, 2000.

Forster, P., Ramaswamy, V., Artaxo, P., Bernsten, T., Betts, R., Fahey, D., Haywood, J., Lean, J., Lowe, D., Myhre, G., Nganga, J., Prinn, R., Raga, G., Schulz, M., and Van Dorland, R.: Changes in Atmospheric Constituents and in Radiative Forcing, in: Climate Change 2007: The Physical Science Basis. Contribution of the Working Group I to the Fourth Assessment Report of the Intergovernmental Panel on Climate Change, edited by: Solomon, S., Qin, D., Manning, M., Chen, Z., Marquis, M., Averyt, K., Tignor, M., and Miller, H., 129-234, Cambridge University Press, Cambridge, United Kingdom and New York, NY, USA., 2007.

Giglio, L., Csiszar, I., and Justice, C.: Global distribution and seasonality of active fires as observed with the terra and aqua moderate resolution imaging spectroradiometer (MODIS) sensors, J. Geophys. Res., 111, G02016, doi:10.1029/2005JG000142, 2006.

Goldberg, M., Qu, Y., McMillin, L., Wolf, W., Zhou, L., and Divakarla, M.: AIRS near-real-time products and algorithms in support of operational numerical weather prediction, IEEE T. 
Geosci. Remote, 41, 379-389, 2003.

Herman, M., Deuzé, J.-L., Marchand, A., Roger, B., and Lallart, P.: Aerosol remote sensing from POLDER/ADEOS over the ocean: Improved retrieval using a nonspherical particle model, J. Geophys. Res., 110, D10S02, doi:10.1029/2004JD004798, 2005.

Hess, M., Koepke, P., and Schult, I.: Optical properties of aerosols and clouds: The software package OPAC, B. Am. Meteorol. Soc., 79, 831-844, 1998.

Highwood, E., Haywood, J., Silverstone, M., Newman, S., and Taylor, J.: Radiative properties and direct effect of Saharan dust measured by the C-130 aircraft during Saharan Dust Experiment (SHADE): 2. Terrestrial spectrum, J. Geophys. Res., 108, 8578, doi:10.1029/2002JD002552, 2003.

Karyampudi, V., Palm, S., Reagen, J., Fang, H., Grant, W., Hoff, R., Moulin, C., Pierce, H., Torres, O., Browell, E., and Melfi, S.: Validation of the Saharan dust plume conceptual model using Lidar, Meteosat, and ECMWF Data, B. Am. Meteorol. Soc., 80, 1045-1075, 1999.

Kaufman, Y., Koren, I., Remer, L., Tanré, D., Ginoux, P., and Fan, S.: Dust transport and deposition observed from the terramoderate resolution imaging spectroradiometer (MODIS) spacecraft over the Atlantic Ocean, J. Geophys. Res., 110, D10S12, doi:10.1029/2003JD004436, 2005.

Kim, S.-W., Berthier, S., Chazette, P., Raut, J.-C., Dulac, F., and Yoon, S.-C.: Validation of aerosol and cloud layer structures from the space-borne lidar CALIOP using a ground-based lidar in Seoul, Korea, Atmos. Chem. Phys., 8, 3705-3720, 2008, http://www.atmos-chem-phys.net/8/3705/2008/.

Kinne, S., Lohmann, U., Feichter, J., Schulz, M., Timmreck, C., Ghan, S., Easter, R., Chin, M., Ginoux, P., Takemura, T., Tegen, I., Koch, D., Herzog, M., Penner, J., Pitari, G., Holben, B., Eck, T., Smirnov, A., Dubovik, O., Slutsker, I., Tanré, D., Torres, O., Mishchenko, M., Geogdzhayev, I., Chu, D., and Kaufman, Y.: Monthly averages of aerosol properties: A global comparison among models, satellite data, and AERONET ground data, J. Geophys. Res., 108, 4634, doi:10.1029/2001JD001253, 2003.

Koren, I., Kaufman, Y., Washington, R., Todd, M., Rudich, Y., Vanderlei Martins, J., and Rosenfeld, D.: The Bodélé depression: a single spot in the Sahara that provides most of the mineral dust to the Amazon forest, Environ. Res. Lett., 1, 14005, doi:10.1088/1748-9326/1/014005, 2006.

Koven, C. and Fung, I.: Inferring dust composition from wavelength-dependent absorption in Aerosol Robotic Network (AERONET) data, J. Geophys. Res., 111, D14205, doi:10.1029/2005JD006678, 2006.

Léon, J.-F. and Legrand, M.: Mineral dust sources in the surroundings of the north Indian Ocean, Geophys. Res. Lett., 30, 1309, doi:10.1029/2002GL016690, 2003.

Levy, R., Remer, L., Tanré, D., Kaufman, Y., Ichoku, C., Holben, B., Livingston, J., Russell, P., and Maring, H.: Evaluation of the moderate-resolution imaging spectroradiometer (MODIS) retrievals of dust aerosol over the ocean during PRIDE, J. Geophys. Res., 108, 8594, doi:10.1029/2002JD002460, 2003.

Li, F. and Ramanathan, V.: Winter to summer monsoon variation of aerosol optical depth over the tropical Indian Ocean, J. Geophys. Res., 107, 4284, doi:10.1029/2001JD000949, 2002.

Liu, L. and Mishchenko, M.: Toward unified satellite climatology of aerosol properties: Direct comparisons of advanced level 2 aerosol products, J. Quant. Spectrosc. Ra., 109, 2376-2385, doi:10.1016/j.jqsrt.2008.05.003, 2008.

Maring, H., Savoie, D., Izaguirre, M., and Custals, L.: Vertical distributions of dust and sea-salt aerosols over Puerto Rico during PRIDE measured from a light aircraft, J. Geophys. Res., 108, 8587, doi:10.1029/2002JD002544, 2003a.

Maring, H., Savoie, D., Izaguirre, M., Custals, L., and Reid, J.: Mineral dust aerosol size distribution change during atmospheric transport, J. Geophys. Res., 108, 8592, doi:10.1029/2002JD002536, 2003b.

McConnell, C., Highwood, E., Coe, H., Formenti, P., Anderson, B., Osborne, S., Nava, S., Desboeufs, K., Chen, G., and Harrison, M.: Seasonal variations of the physical and optical characteristics of Saharan dust: Results from the Dust Outflow and Deposition to the Ocean (DODO) experiment, J. Geophys. Res., 113, D14S05, doi:10.1029/2007JD009606, 2008.

Mona, L., Amodeo, A., Pandolfi, M., and Pappalardo, G.: Saharan dust intrusions in the Mediterranean area: Three years of Raman lidar measurements, J. Geophys. Res., 111, D16203, doi:10.1029/2005JD006569, 2006.

Moulin, C. and Chiapello, I.: Evidence of the control of summer atmospheric transport of African dust over the Atlantic by Sahel sources from TOMS satellites (1979-2000), Geophys. Res. Lett., 31, L02107, doi:10.1029/2003GL018931, 2004.

Papayannis, A., Amiridis, V., Mona, L., Tsaknakis, G., Balis, D., Bösenberg, J., Chaikovski, A., De Tomasi, F., Grigorov, I., Mattis, I., Mitev, V., Müller, D., Nickovic, S., Pérez, C., Pietruczuk, A., Pisani, G., Ravetta, F., Rizi, V., Sicard, M., Trickl, T., Wiegner, M., Gerding, M., Mamouri, R., D’Amico, G., and Pappalardo, G.: Systematic lidar observations of Saharan dust over Europe in the frame of EARLINET (2000-2002), J. Geophys. Res., 113, D10204, doi:10.1029/2007JD009028, 2008.

Péquignot, E., Chédin, A., and Scott, N. A.: Infrared Continental Surface Emissivity Spectra Retrieved from AIRS Hyperspectral Sensor, J. Appl. Meteorol. Clim., 47, 1619-1633, doi:10.1175/2007JAMC1773.1, 2008.

Pierangelo, C., Chédin, A., Heilliette, S., Jacquinet-Husson, N., and Armante, R.: Dust altitude and infrared optical depth from AIRS, Atmos. Chem. Phys., 4, 1813-1822, 2004, http://www.atmos-chem-phys.net/4/1813/2004/.

Pierangelo, C., Mishchenko, M., Balkanski, Y., and Chédin, A.: Retrieving the effective radius of Saharan dust coarse mode from AIRS, Geophys. Res. Lett., 32, L20813, doi:10.1029/2005GL023425, 2005.

Prospero, J.: Long-range transport of mineral dust in the global atmosphere: Impact of African dust on the environment of the southeastern United States, P. Natl. Acad. Sci. USA, 96, 33963403, 1999.

Prospero, J. and Carlson, T.: Vertical and areal distribution of Saharan dust over the western equatorial North Atlantic Ocean, J. Geophys. Res., 77, 5255-5265, 1972.

Prospero, J., Glaccum, R., and Nees, R.: Atmospheric transport of soil dust from Africa to South America, Nature, 289, 570-572, 1981.

Prospero, J., Ginoux, P., Torres, O., Nicholson, S., and Gill, T.: Environmental characterization of global sources of atmospheric soil dust identified with the Nimbus-7 total ozone mapping spectrometer (TOMS) absorbing aerosols product, Rev. Geophys., 40(1), 1002, doi:10.1029/2000RG000095, 2002.

Reid, J., Kinney, J., Westphal, D., Holben, B., Welton, E., Tsay, 
S.-C., Eleuterio, D., Campbell, J., Christopher, S., Colarco, P., Jonsson, H., Livingston, J., Maring, H., Meier, M., Pilewskie, P., Prospero, J., Reid, E., Remer, L., Russell, P., Savoie, D., Smirnov, A., and Tanré, D.: Analysis of measurements of Saharan dust by airborne and groundbased remote sensing methods during the Puerto Rico Dust Experiment (PRIDE), J. Geophys. Res., 108, 8586, doi:10.1029/2002JD002493, 2003.

Remer, L., Tanré, D., Kaufman, Y., Ichoku, C., Mattoo, S., Levy, R., Chu, D., Holben, B., Dubovik, O., Smirnov, A., Martins, J., Li, R.-R., and Ahmad, Z.: Validation of MODIS aerosol retrieval over ocean, Geophys. Res. Lett., 29, 1618, doi:10.1029/2001GL013204, 2002.

Remer, L., Kaufman, Y., Tanré, D., Mattoo, S., Chu, D., Martins, J., Li, R.-R., Ichoku, C., Levy, R., Kleidman, R., Eck, T., Vermote, E., and Holben, B.: The MODIS aerosol algorithm, products, and validation, J. Atm. Sci., 62, 947-973, doi:10.1175/JAS3385.1, 2005.

Scott, N. A. and Chédin, A.: A fast line-by-line method for atmospheric absorption computations: the automatized atmospheric absorption atlas, J. Appl. Meteorol., 20, 802-812, 1981.
Stamnes, K., Tsay, S.-C., Wiscombe, W., and Jayaweera, K.: Numerically stable algorithm for discrete ordinate-method radiative transfer in multiple scattering and emitting layered media, Appl. Optics, 27, 2502-2509, 1988.

Vogelmann, A., Flatau, P., Szczodrak, M., Markowicz, K., and Minnett, P.: Observations of large aerosol infrared forcing at the surface, Geophys. Res. Lett., 30, 1655, doi:10.1029/2002GL016829, 2003.

Volz, F.: Infrared optical constants of ammonium sulfate, Sahara dust, volcanic pumice, and flyash, Appl. Optics, 12, 564-568, 1973.

Wald, A., Kaufman, Y., Tanré, D., and Gao, B.-C.: Daytime and nighttime detection of mineral dust over desert using infrared spectral contrast, J. Geophys. Res., 103, 32307-32313, 1998.

Winker, D., Hunt, W., and McGill, M.: Initial performance assessment of CALIOP, Geophys. Res. Lett., 34, L19803, doi:10.1029/2007GL030135, 2007. 